ТЕОРЕТИЧЕСКИЕ ДЕБАТЫ

О СЕКЬЮРИТИЗАЦИИ

И ИХ ВЛИЯНИЕ НА

РАЗРАБОТКУ ПРОГРАММ

ЭМПИРИЧЕСКИХ ИССЛЕДОВАНИЙ

(C) 2021 г.

К. С. Григорьева *

* Институт сочиологии Федерального научно-исследовательского сочиологического центра РАН,

2. Москва, Россия

Цель исследования: ознакомление отечественной аудитории с малоизвестной в России, но чрезвычайно влиятельной за рубежом теорией секьюритизации; анализ основных критических аргументов в пользу переосмысления и уточнения классического варианта данной теории, предложенного учеными Копенгагенской школы; оценка влияния этих аргументов на разработку программ будущих эмпирических исследований.

Методологическая база исследования. Исследование опирается на логику системного анализа и обобщения ключевых теоретических работ в области секьюритизации, выделения основных аналитических положений, имеющих критически важное значение для разработки дизайна соответствующих научных проектов.

Результаты исследования. Для успешного и всестороннего изучения процессов секьюритизации следует совмещать анализ дискурсов и практик (или, в терминологии $Ф$. Бурбо, рутинной и исключительной логики секьюритизации); необходимо учиты-
Tun статьи в журнале - научная

\section{THEORETICAL DEBATE ABOUT SECURITIZATION AND ITS IMPACT ON THE DESIGN OF EMPIRICAL RESEARCH PROGRAMS}

\author{
(C) 2021 \\ K. S. Grigoryeva * \\ * Institute of Sociology of the Federal Center \\ of Theoretical and Applied Sociology of the \\ Russian Academy of Sciences, \\ Moscow, Russia
}

Objective of the study is to acquaint the audience with the theory of securitization, which is little known in Russia, but extremely important abroad; to analyze key critical arguments of rethinking and improving the classical version of this theory proposed by scientists of the Copenhagen school; to assess the impact of these arguments for the development of the program of future empirical studies.

Methodology of the research is based on the logic of the systemic analysis and generalization of key theoretical studies in the field of securitization, emphasizing most important analytical provisions of critical importance to develop the design of corresponding scientific projects.

Research results. To perform a successful and comprehensive study of the securitization processes, the analysis of discourses and practices should be carried out simultaneously (or, in terms defined by $\mathrm{Ph}$. Bourbeau, the logic of exception and the logic of routine); social, his- 
вать социальный, исторический и культурный контекст; наконец, нельзя недооценивать роль аудитории - важнейшего актора, способного оказывать существенное влияние на развитие и успешность секьюритизации.

Перспективы исследования. Статья будет полезна для ученых, интересующихся вопросами безопасности в самых разных сфеpax, включая миграцию, терроризм, политику в отношении меньшинств, экологию, здравоохранение и др. Предложенный теорией секьюритизации подход к осмыслению безопасности не в качестве чего-то объективно данного, а как рискованной самореферентной практики, нередко имеющей негативные последствия, открывает новые увлекательные исследовательские возможности.

Ключевые слова: теория секьюритизации; Копенгагенская школа; критика; исключительная и рутинная логика; контекст; аудитория torical and cultural context should be taken into consideration; finally, the role of the audience should not be underestimated, the audience is the most important actor that can have a significant impact on the development and success of securitization.

Prospects of the study. The article will be useful for scientists who are interested in security aspects in various spheres, including migration, terrorism, minority groups policies, environment, public health and others. The approach to rethink security proposed by the securitization theory as not something objectively given, but as a risky self-referral practice that rarely has negative consequences and opens up new thrilling research opportunities.

Keywords: securitization theory; Copenhagen School; criticism; exceptional and routine logic; context; audience

\section{Введение}

Несмотря на свое доминирующее положение в европейских исследованиях безопасности, теория секьюритизации в классической трактовке Копенгагенской школы ${ }^{1}$ неоднократно подвергалась критике. Существует по крайней мере четыре важных направления критических дебатов:

- о диалектической взаимосвязи исключительной и рутинной логики секьюритизации;

- внутреннем напряжении между перформативностью и интерсубъективностью секьюритизирующих дискурсов;

- недооценке учеными Копенгагенской школы роли социального и исторического контекста;

- слабой проработанности концепта аудитории.

В этом небольшом эссе сначала дается краткое описание теории секьюритизации. Затем последовательно рассматриваются все четыре критические дискуссии. В заключительной части делаются некоторые выводы о том, что они дают для эмпирического изучения секьюритиза-

${ }^{1}$ Группа ученых, аффилированных с Копенгагенским институтом исследований мира и Копенгагенским университетом. Наиболее известные представители: Б. Бьюзен и О. Вейвер. 
ции и как эта критика должна быть учтена в соответствующих исследовательских программах.

\section{Теория секьюритизации: классическая версия}

Классический вариант теории секьюритизации разработан исследователями Копенгагенской школы. В этой интерпретации секьюритизация рассматривается как перформативный речевой акт ${ }^{1}$, который, будучи принят аудиторией, выводит тот или иной вопрос за рамки нормальной политики. При этом неважно, является ли последний объективной угрозой безопасности. Процесс секьюритизации превращает любой вопрос в проблему безопасности, навешивая на него ярлык экзистенциальной угрозы. Безопасность, таким образом, представляется не в качестве чего-то объективно данного, к чему всегда следует стремиться, но как рискованная самореферентная практика, «стабилизирующая конфликтные или угрожающие отношения, часто через чрезвычайную мобилизацию государства» (Buzan, 1998. Р. 4).

Ключевыми понятиями теории секьюритизации являются:

- референтный объект - «то, что постулируется как имеющее потребность в выживании и находящееся в настоящее время под угрозой»;

- секьюритизирующий субъект - «тот, кто делает аргумент об угрозе референтному объекту»;

- аудитория - «те, кого нужно убедить, чтобы секьюритизация прошла успешно»;

- функциональные субъекты - центральные субъекты, которые не участвуют в секьюритизации, но оказывают значительное влияние на динамику того или иного сектора безопасности ${ }^{2}$. Например, загрязняющая компания в экологическом секторе (Waever, 2003. P. 11-12).

Изучение секьюритизации, согласно представителям Копенгагенской школы, должно осуществляться при помощи анализа дискурсов и политических констелляций. Обнаружение секьюритизирующих дискурсов возможно посредством выявления их специфической риторической структуры, для которой характерно постулирование задачи выживания, срочности и превалирования действий над обсуждением. Основной исследовательский вопрос заключается в следующем: «Когда аргумент с этой конкретной риторической и семиотической структурой достигает достаточного эффекта, чтобы заставить аудиторию терпеть

${ }^{1}$ То есть речевой акт, равный действию.

2 Б. Бьюзен, О. Вейвер и Я. де Вайльд выделяют пять секторов безопасности: военный, экологический, экономический, социальный и политический, каждый из которых имеет собственную повестку (Buzan, 1998). 
нарушения правил, которые в противном случае были бы соблюдены?» (Buzan, 1998. P. 25).

\section{Секьюритизация: исключительные дискурсы или рутинные практики?}

Лингвистический подход Копенгагенской школы оспаривается так называемой Парижской школой - группой французских ученых, сформировавшейся вокруг Д. Биго, отстаивающего приоритет секьюритизирующих практик перед дискурсами. Этот давний спор восходит ещё к 1990-м гг., когда теория секьюритизации находилась в стадии формирования. Хотя обе исследовательские группы придерживаются сходного типа рассуждений (рассматривая безопасность не как объективное благо, а как социально-политическую конструкцию, часто легитимирующую применение насилия) (Bigo, 2018), данная дискуссия затянулась более чем на двадцать лет, и точка в ней до сих пор не поставлена. Иногда накал страстей достигает высоких значений и конкурирующие стороны делают довольно резкие замечания в адрес оппонентов. В частности, Д. Биго пишет, что «такие люди, как Бьюзен, плохо понимают рутину, повседневную практику бюрократии, необходимую для осознания того, как дискурсы работают на практике» (Bigo, 2002. Р. 73). В то же время Ф. Бурбо с иронией отмечает: «Многие аспиранты скрежещут своими теоретическими зубами в этих дебатах» (Bourbeau, 2014. P. 187). Впрочем, на сегодняшний день обе позиции так же далеки от победы, как и двадцать лет назад, и все больше ученых, проводящих эмпирические исследования секьюритизации, переходят к совмещенному анализу дискурсов и практик. Фундированное теоретическое обоснование подобного синтезированного подхода дал в своей работе «Движение вперед вместе: логика процесса секьюритизации» Ф. Бурбо. Утверждая, что взятые по отдельности обе исследовательские позиции имеют неустранимые недостатки, он призывает к объединению усилий конкурирующих сторон для получения более полной картины секьюритизации. Дело в том, что как логика исключения, так и логика рутины описывает только одну сторону медали. Сосредотачиваясь на пиковых моментах секьюритизации (речевые акты, выводящие проблему за рамки нормальной политики), сторонники Копенгагенской школы упускают из виду множество менее заметных, но отнюдь не менее важных недискурсивных секьюритизирующих практик. В то же время фокусировка приверженцев Парижской школы на рутинных практиках профессионалов безопасности не позволяет увидеть развитие процесса секьюритизации, делая его плоским и лишенным динамики. Одновременное изучение дискурсив- 
ных и недискурсивных элементов секьюритизации помогает избежать подобной односторонности.

\section{Перформативность и интерсубъективность секьюритизирующего речевого акта}

Другое важное направление критических дискуссий - это внутреннее напряжение между перформативностью и интерсубъективностью секьюритизирующего речевого акта.

Перформативность секьюритизации формулируется О. Вейвером следующим образом: «Процесс секьюритизации - это речевой акт. Он не интересен как знак, отсылающий к чему-то более реальному: само высказывание есть акт. Произнося эти слова, вы что-то делаете (например, даете клятву, заключаете пари, называете корабль). Произнося: "Прошу прощения за свое поведение", говорящий на самом деле просит прощения; он не описывает себя извиняющимся за свое поведение» (Waever, 2003. Р. 10). Этот пассаж позволяет Т. Бальзаку, одному из критиков теории секьюритизации в интерпретации Копенгагенской школы, утверждать, что её представители придают секьюритизирующему речевому акту «магическую эффективность» (Balzacq, 2005. Р. 177) и одновременно сводят секьюритизацию к формальной процедуре, такой как брак или пари (Balzacq, 2005. Р. 172). При этом перформативность секьюритизирующего речевого акта вступает в противоречие с интерсубъективностью секьюритизации (её зависимостью от реакции аудитории), неоднократно подчеркиваемой О. Вейвером и Б. Бьюзеном.

Сходной позиции придерживается Х. Стритцель. Он отмечает, что в рассуждениях О. Вейвера о перформативности секьюритизирующих речевых актов, помимо опоры на Дж. Остина, отчетливо прослеживается влияние таких философов, как Ж. Деррида и Дж. Батлер. Разделяемое О. Вейвером знаменитое заявление Ж. Деррида о том, что «нет ничего вне текста», впоследствии развитое Дж. Батлер в смысле способности речевых актов конструировать социальные отношения, позволяет Х. Стритцелю предположить, что Копенгагенская школа делает основной акцент на семантической стороне артикуляции речевого акта. Однако дерридарианская/батлеровская позиция, обозначаемая Х. Стритцелем как «интерналистская», находится в явной оппозиции к «экстерналистской» идее об интерсубъективности секьюритизации, поскольку в постмодернистской и постструктуралистской интерпретации никакого социального процесса не существует, есть только «свободно плавающий текст» и его внутренняя повторяемость. Таким образом, выбирая интерналистскую интерпретацию се- 
кьюритизации, Копенгагенская школа вынуждена жертвовать интерсубъективностью, и наоборот (Stritzel, 2007).

Близкие соображения высказывает и M. Макдональд. С одной стороны, он подчеркивает проблематичность представления языка как исключительной формы секьюритизации, поскольку последняя может осуществляться не только через речь, но также посредством изображений ${ }^{1}$ и практик ${ }^{2}$. С другой стороны, М. Макдональд, аналогично Т. Бальзаку и Х. Стритцелю, усматривает логическое противоречие между утверждениями представителей Копенгагенской школы об одновременной перформативности и интерсубъективности секьюритизирующего дискурса. В конечном счете, полагает он, сторонники лингвистического подхода должны прояснить свою позицию, преуменьшив либо перформативную силу речевых актов, либо интерсубъективный характер секьюритизации (McDonald, 2008. P. 573).

\section{Дебаты о контексте}

С вопросом о соотношении перформативности и интерсубъективности секьюритизации тесно связана дискуссия о контексте. Хотя ученые Копенгагенской школы учитывают некоторые контекстуальные условия, необходимые для успешности секьюритизации (социальный капитал субъекта секьюритизации; согласие аудитории; особенности предполагаемых угроз, которые могут облегчать/затруднять секьюритизацию; различия между секторами безопасности и т. д.), критики полагают, что этого недостаточно. В частности, Х. Стритцель убежден, что теории секьюритизации следует выйти за рамки узко понимаемой «социальной магии» речевого акта и концептуализировать глубокую укорененность артикуляции безопасности в социальных отношениях власти (Stritzel, 2007. Р. 365). В настоящее время, отмечает он, тезис о взаимном влиянии акторов и социальных структур фактически является общепризнанным. Акторы находятся в структурированном контексте, который ограничивает их способность реализовать свои намерения, но на который они, в свою очередь, оказывают влияние через последствия своих действий. Исходя из этого структурационистского понимания, Х. Стритцель стремится реконцептуализировать теорию секьюритизации таким образом, чтобы она позволяла осмыслить взаимосвязь агентов, структур и текста ${ }^{3}$, учитывая взаимную конститутивность их существо-

\footnotetext{
${ }^{1}$ См., к примеру, известную статью М.С. Вильямса «Слова, образы, враги: секьюритизация и международная политика» (Williams, 2003).

2 О секьюритизации через практики см. более подробно коллективную работу «Практики безопасности» (Balzacq, 2010).

${ }^{3}$ Х. Стритцель вводит понятие «текст», заменяя им понятие «речевой акт», чтобы подчеркнуть его не одномоментный, развивающийся характер.
} 
вания и несводимость к простой сумме структурных, агентурных и текстовых факторов. При этом предлагается различать социальнолингвистические и социально-политические аспекты контекста. Социолингвистический аспект подразумевает связь конкретного текста с сетью конститутивных правил и нарративов, действующих в данное время. Актор секьюритизации ограничен этими социолингвистическими условиями и вынужден формулировать свои аргументы в рамках лингвистического резервуара, доступного в конкретный момент. Социополитический аспект контекста связан с отношениями власти ${ }^{1}$ и её неравным распределением между акторами, ограничивающим/повышающим их способность достичь успешной секьюритизации того или иного вопроса. Секьюритизация, таким образом, оказывается встроенной в исторически изменчивые структуры значения и власти, с акцентом на существующем дискурсе, дающем преимущество одним аргументам и акторам перед другими.

Утверждение о том, что Копенгагенская школа уделяет проблематично мало внимания социальному и политическому контексту секьюритизации, разделяется М. Макдональдом. На его взгляд, за рамками теоретических построений копенгагенской группы ученых остаются такие важные вопросы, связанные с контекстуальными факторами: почему некоторые политические сообщества с большей вероятностью рассматривают определенных действующих лиц и динамику как угрожающие? Какую роль играют нарративы истории, культуры и идентичности в обосновании или легитимации конкретных форм секьюритизации? В какой степени возможность секьюритизации определяется целевой аудиторией речевых актов? Как некоторые голоса наделяются полномочиями или маргинализируются для определения безопасности и угрозы? (McDonald, 2008. P. 573).

Наконец, Т. Бальзак, также разочарованный недостатком внимания, уделяемого Копенгагенской школой внешним (недискурсивным) условиям секьюритизации, предлагает рассматривать её не как формальный речевой акт, а как стратегическую практику, для успешности которой решающее значение имеет контекст. Чтобы продемонстрировать продуктивность своего подхода, Т. Бальзак приводит пример Папистского заговора. В действительности упомянутый заговор никогда не существовал, но, будучи сфабрикованным лжесвидетелем Т. Оутсом, заявившим, что католики собирались убить короля Карла II, возвести на престол его брата-католика и перебить протестантов, привел к антикато-

${ }^{1}$ Отношения власти одновременно влияют на развитие дискурса и подвергаются реконфигурации под воздействием его трансформации. 
лической истерии среди протестантского населения Англии в конце 1670-х гг. В результате несколько человек было казнено за государственную измену и был принят закон об исключении католиков из обеих палат парламента. Несмотря на отсутствие реальной угрозы, подчеркивает Т. Бальзак, заговор произвел большое впечатление на протестантов, которые с помощью своих судов и своего парламента в кратчайшие сроки устранили эту воображаемую опасность. Данный случай показывает, как лингвистический контент может изменять существующий контекст, представляя ту или иную группу в качестве угрозы. На первый взгляд, это подтверждает перформативную силу секьюритизирующего речевого акта, не зависящую от реальных обстоятельств, и укладывается в определение безопасности как самореферентной практики. Однако углубленный анализ описанного случая демонстрирует, что подобная интерпретация открывает лишь часть более сложной картины. Чтобы понять, почему протестанты согласились с версией Т. Оутса, следует изучить не только сам дискурс, но и более широкий контекст Англии XVII в. Здесь необходимо отметить по крайней мере три важных контекстуальных фактора: пожар в Лондоне 1666 г., за который, как считали английские протестанты, несли ответственность католики; недовольство тем, что брат короля, будучи католиком, может унаследовать престол; ощущаемая угроза со стороны французского короля-католика Людовика XIV, недавно вторгшегося в Нидерланды и усилившего свою власть в Испании. Именно с помощью целенаправленного использования этого контекста Оутс добился широкой поддержки своей истории о заговоре. Таким образом, подытоживает Т. Бальзак, семантический репертуар безопасности представляет собой сочетание текстового значения (знания концепции, приобретенного с помощью письменного или устного языка) и культурного значения (знания, полученного в результате предыдущих взаимодействий и ситуаций). Только тот дискурс, который резонирует с контекстом, будет признан и поддержан аудиторией (Balzacq, 2005. P. 180-183).

\section{Дебаты об аудитории}

Интенсивные дебаты ведутся и вокруг концепта «аудитория». Хотя аудитория является одним из центральных элементов теории секьюритизации, критики полагают, что представление о ней остается чрезмерно размытым и неопределенным. С этим соглашаются и сами представители Копенгагенской школы. В частности, О. Вейвер пишет, что понятие «аудитория» нуждается «в более четком определении и, возможно, дифференциации» (Waever, 2003. P. 26). 
По мнению Т. Бальзака, несмотря на то что «Копенгагенская школа обращается к аудитории, её структура игнорирует эту аудиторию» (Balzacq, 2005. Р. 177). Между тем успешность секьюритизации в значительной степени обусловлена способностью секьюритизатора идентифицировать себя с чувствами, потребностями и интересами аудитории. Т. Бальзак выделяет два вида поддержки, к которой чувствителен субъект секьюритизации: формальная и моральная. Формальная поддержка исходит от официальных учреждений, в то время как моральная - от более широкой неинституционализированной аудитории. Как правило, моральная поддержка необходима, но недостаточна. Лишь официальное решение уполномоченного учреждения (парламент, конгресс, Совета Безопасности $\mathrm{OOH}$ и т. д.) позволяет принять конкретную политику. Вместе с тем получение формальной поддержки в отсутствие моральной поддержки может разорвать связь с избирателями и иметь негативные последствия в будущем. Это объясняет стремление субъекта секьюритизации завоевать как можно более широкую аудиторию. В итоге чем более согласованной формальной и моральной поддержки секьюритизатору удается достичь, тем больше вероятность, что секьюритизация пройдет успешно (Balzacq, 2005. P. 184-186).

Теоретическая разработка Т. Бальзака о моральной и формальной поддержке была применена П. Роу в известном тематическом исследовании, посвященном решению Великобритании вторгнуться в Ирак в 2003 г. При этом П. Роу реконцептуализировал как положения Т. Бальзака, так и подход Копенгагенской школы, представив секьюритизацию в виде двухэтапного процесса, распадающегося на стадию идентификации (когда создается платформа, с помощью которой можно узаконить чрезвычайные меры) и стадию мобилизации (когда чрезвычайные меры действительно принимаются). Это сделано для того, чтобы более точно описать саму секьюритизацию, состоящую, по убеждению П. Роу, не только из риторической, но и из активной фазы, а также нюансировать реакцию аудитории. В рассматриваемом случае британская общественность первоначально согласилась с тем, что иранское ядерное оружие представляет экзистенциальную угрозу, но не поддержала предложение о принятии чрезвычайных мер в виде начала войны. Вторжение в Ирак стало возможным только на втором этапе, когда в необходимости подобной меры удалось убедить другую аудиторию - парламент. Таким образом, моральная поддержка избирателей сыграла свою роль на стадии идентификации, однако на стадии мобилизации ключевое значение имела формальная поддержка, тогда как мнение широкой общественности было попросту проигнорировано (Roe, 2008). 
М. Б. Солтер предложил драматургический подход к анализу секьюритизации, настаивая на том, что не существует единого секьюритизирующего речевого акта и единой аудитории. Напротив, есть большой репертуар секьюритизирующих дискурсов, настроенных на разные аудитории. М. Б. Солтер выделяет четыре типа аудитории: массовую, элитарную, технократическую и научную, заключающие в себе, соответственно, широкую общественность, политические элиты, бюрократов и ученых. На примере тематического исследования секьюритизации безопасности канадской гражданской авиации автор демонстрирует радикальные различия в языковых и политических играх, захватывающих каждую из этих аудиторий. Опираясь на драматургическую модель И. Гофмана, М. Б. Солтер рассматривает процесс секьюритизации как своего рода представление, где важно понимать, что происходит на сцене и за кулисами. В частности, между собой (за кулисами) секьюритизирующие субъекты могут говорить совершенно иначе, нежели с той или иной аудиторией (на сцене), под чьи ожидания они вынуждены подстраиваться. При этом перед разными аудиториями зачастую выступают разные субъекты секьюритизации, наделенные наиболее релевантными полномочиями. В анализируемом М. Б. Солтером случае один и тот же шаг по секьюритизации авиационной безопасности и безопасности пассажиров в аэропортах был сделан разными секьюритизаторами для разных аудиторий с употреблением разных аргументов и с разными результатами. Важный вывод исследования состоит в том, что решающая роль в успехе секьюритизации, безусловно, принадлежит аудиториям: они могут не только соглашаться или не соглашаться с предложениями секьюритизаторов, но и инициировать расширение или сворачивание процессов секьюритизации (Salter, 2008).

Обобщающую работу по концептуализации аудитории провел А. Коте. Осуществив метасинтез 32 эмпирических исследований секьюритизации, он пришел к выводу, что теоретическое описание аудитории, предложенное учеными Копенгагенской школы, значимо отличается от того, которое представляется авторами, опирающимися на эмпирические данные. Если первые изображают аудиторию как пассивного адресата аргументов секьюритизатора, вторые характеризуют её как активную и заинтересованную. Аналитически работа А. Коте касается двух основных вопросов: кто является аудиторией и как аудитория участвует в построении безопасности? Отмечая довольно высокую вариативность представления о том, кого следует понимать в качестве аудитории (от широкой общественности до отдельных ветвей власти, местных элит, спонсоров, коллег по организации и т. д.), А. Коте подчеркивает, что во 
многих исследованиях предполагается существование множества аудиторий. При этом идентичность аудитории зачастую зависит от контекста секьюритизации и от различной способности тех или иных групп или субъектов легитимировать действия, к которым стремится секьюритизатор. Кроме того, эмпирические исследования демонстрируют центральную роль аудитории в процессе секьюритизации. Во-первых, секьюритизатор и аудитория участвуют в повторяющихся контекстуально опосредованных взаимодействиях, как правило, приводящих к изменению поведения субъекта секьюритизации, стремящегося к получению поддержки аудитории. Во-вторых, аудитория активно участвует в самом процессе секьюритизации. Чаще всего она оспаривает представление проблемы, предложенное секьюритизатором, вынуждая его либо отказаться от своих намерений, либо совершить очередной секьюритизирующий ход. Во многих случаях действия аудитории оказывают прямое влияние на политические результаты. Причем это влияние может быть как десекьюритизирующим, так и многократно увеличивающим степень и срочность секьюритизации. Таким образом, аудитория ни в коем случае не является ни пассивной, ни полностью зависимой от контекста. Хотя контекстуальные правила успеха или неудачи секьюритизации важны, аудитория не всегда их придерживается, активно вовлекая участников секьюритизации во взаимно обусловленные социальные, бюрократические и лингвистические обстоятельства, которые (вос)создаются и преобразуются в результате этого взаимодействия (Côté, 2016. P. 11).

\section{Теория секьюритизации и эмпирические исследования}

Теория секьюритизации успешно применялась во многих исследовательских областях, в том числе в изучении проблем экологии, здравоохранения, прав меньшинств, войны с терроризмом, особенно интенсивно в миграционных исследованиях (McDonald, 2008; Balzacq, 2010).

Хотя российские ученые пока практически не обращаются к теории секьюритизации, стремительное развитие исследований секьюритизации за пределами Центральной и Северной Европы, где они зародились, позволяет предположить, что эта ситуация вскоре изменится. Чтобы не повторять долгий и уже пройденный за рубежом путь от классической теории секьюритизации к её более современным вариантам, при разработке программ соответствующих исследований следует учитывать критику, рассмотренную выше. В частности, необходимо иметь в виду, что процесс секьюритизации не исчерпывается секьюритизирующими дискурсами. Для углубленного изучения необходимо совмещать анализ 
дискурсов с исследованием секьюритизирующих практик. Не следует чрезмерно концентрироваться на изолированных речевых актах. Как показали критические дебаты, важную роль играет также социальный, исторический и культурный контекст, в котором они совершаются. Наконец, не стоит недооценивать роль аудитории(ий). Для успеха секьюритизации она является решающей. Аудитории не только соглашаются или отвергают аргументацию секьюритизатора, но и активно участвуют в процессе секьюритизации, нередко меняя его направление, интенсивность, срочность и содержательное наполнение.

\section{Литература / References}

Balzacq, T. (2005). The Three Faces of Securitization: Political Agency, Audience and Context. European Journal of International Relations, 11, 2, 171-201.

Balzacq, T., Başaran, T., Bigo, D., Guittet, E.-P., Olsson, C. (2010). Security Practices. In The International Studies Encyclopedia Online. R. A. Denemark (Ed.). Available at: https://is.muni.cz/el/fss/podzim2015/ESS419/um/Balzaq_et_al_2010.pdf.

Bigo, D. (2002). Security and Immigration: Toward a Critique of the Governmentality of Unease. Alternatives, 27, 63-92.

Bigo, D., McCluskey, E. (2018). What Is a PARIS Approach to (In)securitization? Political Anthropological Research for International Sociology. In The Oxford Handbook of International Security. A. Gheciu, W.C. Wohlforth (Eds.). Available at: https:// www.oxfordhandbooks.com/ view/10.1093/oxfordhb/9780198777854.001.0001/oxfordhb-9780198777854-e-9.

Bourbeau, Ph. (2014). Moving Forward Together: Logics of the Securitisation Process. Millennium: Journal of International Studies, 43, 1, 187-206.

Buzan, B., Weever, O., De Wilde, J. (1998). Security: A New Framework for Analysis. Boulder, CO: Lynne Reiner.

Côté, A. (2016). Agents without agency: Assessing the role of the audience in securitization theory. Security Dialogue, 47, 6, 1-18.

McDonald, M. (2008). Securitization and the Construction of Security. European Journal of International Relations, 14, 4, 563-587.

Roe, P. (2008). Actor, Audience(s) and Emergency Measures: Securitization and the UK's Decision To Invade Iraq. Security Dialogue, 39, 6, 615-635.

Salter, M. B. (2008). Securitization and desecuritization: a dramaturgical analysis of the Canadian Air Transport Security Authority. Journal of International Relations and Development, 11, 4, 321-349.

Stritzel, H. (2007). Towards a Theory of Securitization: Copenhagen and Beyond. European Journal of International Relations, 13, 3, 357-383.

Weever, $O$. (2003). Securitisation: Taking stock of a research programme in Security Studies. Unpublished manuscript. DOCPLAYER. Available at: https://docplayer.net/62037981Securitisation-taking-stock-of-a-research-programme-in-security-studies.html.

Williams, M.C. (2003). Words, Images, Enemies: Securitization and International Politics. International Studies Quarterly, 47, 511-531. 
Для цитирования: Григорьева К. С. Теоретические дебаты о секьюритизации и их влияние на разработку программ эмпирических исследований // Гуманитарий Юга

России. 2021.5 (51). С. 217-229.

DOI 10.18522/2227-8656.2021.5.15

\section{Сведения об авторе}

\section{Григорьева Ксения Сергеевна}

Кандидат социологических наук, старший научный сотрудник, Институт социологии Федерального научно-исследовательского социологического центра РАН

117218, г. Москва, ул. Кржижановского, 24/35, корп. 5, e-mail: ksenia_grig@mail.ru
История статьи: Поступила в редакцию - 03.10.2021 г. Получена в доработанном виде 29.10.2021 г. Одобрена - 12.11.2021 г.

\section{Information about author}

\section{Ksenia Sergeevna Grigoryeva}

Candidate of Sociological Sciences, Senior Researcher, Institute of Sociology, Federal Center of Theoretical and Applied Sociology of the Russian Academy of Sciences

24/35 Krzhizhanovskogo St., Bld. 5, Moscow, 117218, e-mail: ksenia_grig@mail.ru 